\title{
Effects of ruminal doses of sucrose, lactose, and corn starch on ruminal fermentation and expression of genes in ruminal epithelial cells
}

\author{
M. Oba, ${ }^{1}$ J. L. Mewis, and Z. Zhining \\ Department of Agricultural, Food and Nutritional Science, University of Alberta, Edmonton, AB T6G 2P5, Canada
}

\begin{abstract}
The objective was to evaluate effects of a ruminal dose of sucrose, lactose, and corn starch on ruminal fermentation and expression of genes in ruminal epithelial cells. Six ruminally cannulated nonlactating nonpregnant Holstein cows (body weight $=725 \pm 69.6 \mathrm{~kg}$ ) were assigned to treatments in a $3 \times 3$ Latin square design with 7 -d periods; $1 \mathrm{~d}$ for data and sample collection followed by a 6 -d washout period. Cows were fed a diet containing whole-crop barley silage and dry ground corn, and dietary neutral detergent fiber and crude protein contents were 41.8 and $13.2 \%$ [dry matter (DM) basis], respectively. Treatment was a pulse-dose of sucrose, lactose, and corn starch (3.0, 3.0, and 2.85 $\mathrm{kg}$ of DM, respectively; providing similar amounts of hexose across the treatments) through the ruminal cannulas. All treatments were given with alfalfa silage $(1.75 \mathrm{~kg} \mathrm{DM})$ to prevent acute rumen acidosis. Rumen $\mathrm{pH}$ was continuously monitored, and rumen fluid was sampled at $0,30,60,90,120,150$, and $180 \mathrm{~min}$ after the dose. In addition, ruminal papillae were sampled from the ventral sac at 180 min after the dose. Ruminal dosing with sucrose and lactose, compared with corn starch, increased ruminal total volatile fatty acid concentration and molar proportion of butyrate from 60 to $180 \mathrm{~min}$ after the dose, and expression of genes for sodium hydrogen exchanger isoforms 1 and 2, and ATPase isoform 1 in ruminal epithelial cells. Ruminal dosing with sucrose, compared with lactose and corn starch, decreased rumen $\mathrm{pH}$ from 120 to 180 min after the dose and molar proportion of acetate in ruminal fluid from 60 to $150 \mathrm{~min}$ after the dose, and increased molar proportion of propionate in ruminal fluid from 60 to $150 \mathrm{~min}$, and expression of genes involved in butyrate metabolism (3-hydroxy-3-methylglutaryl-coenzyme A synthase isoform 1) and anion exchange across ruminal apical cell membrane (putative anion transporter isoform 1). These results suggest that replacing dietary starch with sugars may affect ruminal fermentation and
\end{abstract}

Received August 1, 2014.

Accepted September 4, 2014.

${ }^{1}$ Corresponding author: moba@ualberta.ca metabolism regulating intracellular $\mathrm{pH}$ and fermentation acid absorption in ruminal epithelial cells, and that these effects can be greater for sucrose than lactose. Key words: sucrose, lactose, starch, volatile fatty acids, gene expression

\section{INTRODUCTION}

Sugars are part of the carbohydrates fed in diets of lactating dairy cows. Sugars ferment quickly in the rumen; Sniffen et al. (1992) estimated that sugars ferment at $300 \% / \mathrm{h}$, whereas the fermentation rate of starch varies from 15 to $40 \% / \mathrm{h}$ depending on grain types and processing methods. Weisbjerg et al. (1998) showed that hydrolysis rates of sugars varied from 248 to $1,404 \% / \mathrm{h}$, and that they ferment almost completely (i.e., $>95 \%$ ) in the rumen. Replacing dietary starch with sugars often increases DMI (DeFrain et al., 2004; Broderick et al., 2008; Penner and Oba, 2009) and milk fat production (Broderick et al., 2008; Penner and Oba, 2009); however, its mode of action is not well understood. Despite rapid fermentation, according to a review by Oba (2011), the majority of in vivo studies reported that rumen $\mathrm{pH}$ is not affected by feeding sugars, and a few studies reported that replacing a dietary starch source with sugars increased rumen $\mathrm{pH}$ (Chamberlain et al., 1993; Heldt et al., 1999) or tended to increase rumen $\mathrm{pH}$ (Penner et al., 2009; Penner and Oba, 2009). In addition, the effects of feeding sugars on the VFA profile in rumen fluid are not consistent. Although in vitro studies suggested that sugar fermentation increases butyrate production (Vallimont et al., 2004; Ribeiro et al., 2005), in vivo studies reported considerably variable effects of sugar feeding on VFA profile as summarized by Oba (2011).

The discrepancy between expected and observed rumen fermentation variables can be partly attributed to data and sample collection protocols. Rumen $\mathrm{pH}$ data are usually measured continuously and summarized on a daily basis to account for diurnal variation. Similarly, when the VFA profile of rumen fluid is determined, in most studies, multiple samples are composited to account for diurnal variation. However, this data may not reflect how sugars ferment in the rumen because 
most of dietary sugars are expected to ferment immediately after consumption by animals. In addition, the absorption rate of butyrate is faster than that of acetate or propionate (Leek, 1993), and it may be difficult to detect increases in butyrate concentration in rumen fluid even if sugar fermentation increases butyrate production in the rumen. Furthermore, butyrate concentration in rumen fluid may not necessarily reflect its production because the former is also affected by absorption and passage of butyrate.

It is necessary to identify short-term effects of feeding sugars on rumen fermentation to elucidate mechanisms on how sugar feeding affects animal performance. In addition, although ruminal epithelial metabolism can affect VFA absorption and rumen $\mathrm{pH}$ (Aschenbach et al., 2011), effects of feeding sugars on the metabolism of ruminal epithelial cells have not been extensively studied. Furthermore, effects of sugar type on ruminal fermentation and metabolism in ruminal epithelial cells are not well understood. As such, objectives of the current study were to determine short-term effects of ruminal doses of sucrose and lactose on rumen fermentation and gene expression in ruminal epithelial cells compared with ruminal doses of starch, the most common NFC in dairy diets.

\section{MATERIALS AND METHODS}

The current study was conducted from June 2013 to July 2013 at the University of Alberta Dairy and Research Technology Center. Animals used in this study were cared for in agreement with the guidelines of the Canadian Council on Animal Care (Ottawa, ON, Canada). All experimental procedures were approved by the University of Alberta Animal Care and Use Committee for Livestock (\# AUP580).

\section{Experimental Design}

Six multiparous nonlactating nonpregnant Holstein cows (BW $725 \pm 69.6 \mathrm{~kg}$; mean $\pm \mathrm{SD}$ ) were used in this study. All cows were ruminally cannulated for previous studies, and were housed in individual stalls bedded with wood shavings. The cows were fed a TMR (Table 1), once daily at $0800 \mathrm{~h}$, ad libitum allowing for $5 \%$ refusals throughout the trial, and had free access to water. Dry matter intake was $12.2 \pm 0.79 \mathrm{~kg} / \mathrm{d}$ (mean $\pm \mathrm{SD}$ ) during the study. After 21-d diet adaptation, cows were assigned to treatments in a duplicated $3 \times$ 3 Latin square design, balanced for carryover effects, with 7-d periods; $1 \mathrm{~d}$ for data and sample collection, followed by a 6 -d washout period. Treatments were ruminal doses of corn starch, sucrose, and lactose (2.85, 3.00 , and $3.00 \mathrm{~kg}$ of $\mathrm{DM}$, respectively, to provide the
Table 1. Ingredients and chemical composition of the diet fed during the study

\begin{tabular}{lc}
\hline Item & Measurement \\
\hline Ingredients composition, \% of DM $^{1}$ & \\
Barley silage & 82.6 \\
Dry ground corn & 5.6 \\
Canola meal & 5.3 \\
Sucrose & 2.1 \\
Lactose & 2.1 \\
Salt & 0.8 \\
Canola oil & 0.6 \\
Limestone & 0.4 \\
Calcium diphosphate & 0.4 \\
Magnesium oxide & 0.2 \\
Vitamin ADE premix ${ }^{2}$ & 0.019 \\
Selenium & 0.008 \\
Trace mineral premix & 4 \\
Nutrient composition & 0.007 \\
DM, \% & \\
CP, \% of DM & 39.3 \\
NDF, \% of DM & 11.4 \\
NFC, \% of DM & 40.4 \\
\hline
\end{tabular}

${ }^{1} \mathrm{DM}$ : 34.9\%; CP: 14.4\%DM; NDF: 51.8\%DM; starch 9.8\%DM.

${ }^{2}$ Contained $60,000 \mathrm{kIU} / \mathrm{kg}$ of vitamin A, $6,000 \mathrm{kIU} / \mathrm{kg}$ of vitamin D, $20 \mathrm{kIU} / \mathrm{kg}$ of vitamin E.

${ }^{3}$ Contained 2,000 $\mathrm{mg} / \mathrm{kg}$ of Se.

${ }^{4}$ Contained $133,400 \mathrm{mg} / \mathrm{kg}$ of $\mathrm{Cu}, 240,000 \mathrm{mg} / \mathrm{kg}$ of $\mathrm{Mn}, 2,700 \mathrm{mg} / \mathrm{kg}$ of $\mathrm{Co}, 20,000 \mathrm{mg} / \mathrm{kg}$ of $\mathrm{Zn}$, and $6,000 \mathrm{mg} / \mathrm{kg}$ of I.

same amount of hexoses). On each data collection day, treatment carbohydrates were manually dosed into the rumen at $0800 \mathrm{~h}$ with $1.75 \mathrm{~kg}$ of alfalfa silage (DM basis), to minimize the risk of rumen acidosis. Data and samples were collected for $3 \mathrm{~h}$ following the ruminal dose, and cows were subsequently fed the diet at 1130 $\mathrm{h}$ after data and sample collection was completed.

\section{Data and Sample Collection}

Rumen $\mathrm{pH}$ was measured every $30 \mathrm{~s}$ over a 4 -h period, from $1 \mathrm{~h}$ before the treatment dose to $3 \mathrm{~h}$ after the dose, using the Lethbridge Research Center ruminal $\mathrm{pH}$ measurement system (Penner et al., 2006), and summarized for each hour. Rumen fluid was sampled, every $30 \mathrm{~min}(0,30,60,90,120,150$, and $180 \mathrm{~min}$ relative to the ruminal dose of treatment), from 5 locations in the rumen (cranial dorsal, cranial ventral, central, caudal dorsal, and caudal ventral) and strained through a perforated fabric screen (WeedBlock, Easy Gardener, Waco, TX). Samples were placed on ice immediately, and centrifuged at $3,000 \times g$ for $20 \mathrm{~min}$ at $4^{\circ} \mathrm{C}$. The supernatant was stored at $-20^{\circ} \mathrm{C}$ until analysis, and subsequently analyzed for VFA profile as described by Khorasani et al. (1996).

Immediately after the last rumen fluid collection (180 min after the treatment dose), rumen contents were evacuated into an insulated container. Then, the ventral sac region of the rumen was pulled out through the rumen cannula, and approximately 30 papillae 
were biopsied using a pair of surgical scissors. Rumen papillae were rinsed with $\mathrm{PBS}$ at $\mathrm{pH} 7.4$, and stored in RNA-Later (Ambion Inc., Foster City, CA) at $-20^{\circ} \mathrm{C}$ until analysis.

Total RNA was extracted from the ruminal papillae samples with the Trizol extraction method (Invitrogen, Burlington, ON, Canada) as described by Chomczynski and Sacchi (1987), and purified using a Qiagen RNeasy MiniElute Cleanup Kit (Qiagen, Toronto, ON, Canada). The RNA samples were diluted to $100 \mathrm{ng} / \mu \mathrm{L}$ and subsequently treated with DNase I (Invitrogen, Carlsbad, CA) and RNase OUT (Invitrogen). First-strand cDNA was synthesized using Superscript II (Invitrogen). Genes encoding monocarboxylate cotransporter, isoform 1 (MCT1), downregulated in adenoma (DRA), putative anion transporter, isoform 1 (PAT1), sodium hydrogen exchanger, isoforms 1, 2, and 3 (NHE1, NHE2, and NHE3, respectively), and $\mathrm{Na}^{+} / \mathrm{K}^{+}$ATPase pump (ATP1), 3-hydroxy 3-methylglutaryl coenzyme A synthase isoforms 1 and 2 (HMGCS1 and HMGCS2, respectively), 3-hydroxy-3-methylglutaryl-CoA lyase ( $H M G$ $C L)$, and $\beta$-hydroxybutyrate dehydrogenase, isoforms 1 and 2 (BDH1 and BDH2, respectively) were evaluated for their expression in ruminal epithelial cells via quantitative real-time PCR, using a TaqMan gene expression assay with The StepOne Plus Real-Time PCR System (Life Technologies, Carlsbad, CA) as described previously (Table 2; Laarman et al., 2012; Schlau et al., 2012) using 3 housekeeping genes, ribosomal protein large, P0, $\beta$-actin, and GADPH, according to the method described by Vandesompele et al. (2002).

Blood was sampled from a jugular vein through a catheter inserted the day before the data collection day every $30 \mathrm{~min}(0,30,60,90,120,150$, and $180 \mathrm{~min}$ relative to the ruminal dose of treatment). Blood samples were immediately placed into tubes containing Na heparin (Becton Dickinson Co., Franklin Lakes, NJ), placed on ice immediately, and then centrifuged at 3,000 $\times g$ for $20 \mathrm{~min}$ at $4^{\circ} \mathrm{C}$. Plasma was harvested and stored at $-20^{\circ} \mathrm{C}$ until analysis. Plasma samples were analyzed for concentrations of glucose, insulin, BHBA, and NEFA as described previously (Sun and Oba, 2014).

Data were analyzed separately for each time point using JMP (version 10, SAS Institute Inc., Cary, NC). The statistical model included fixed effects of treatment and period, and random effect of cow. Treatment effects were declared significant at $P<0.05$ and a tendency was declared at $P<0.10$.

\section{RESULTS}

\section{Rumen Fermentation Variables}

Average rumen $\mathrm{pH}$ for a 60 -min period immediately before the treatment dose was 6.61 , but rumen $\mathrm{pH}$ dur- ing the third hour after the treatment dose (average $\mathrm{pH}$ from 120 to $180 \mathrm{~min}$ ) was lower for sucrose treatment compared with starch and lactose treatments (6.23 vs. 6.59 and 6.47, respectively; Figure 1). Total VFA concentration in rumen fluid is greater for sucrose and lactose treatments compared with starch at 60 to 180 min after the treatment dose (Figure 2), and for sucrose compared with lactose transiently at 90 and $150 \mathrm{~min}$. The molar proportion of acetate was lower and that of propionate was higher for cows dosed with sucrose compared with those dosed with starch and lactose at 60 to 180 min after the dose (Figure 3). However, differences in the molar proportion of butyrate were observed between lactose and starch treatments; it was highest for sucrose treatment, followed by lactose and starch treatments since 30 min after the treatment dose. Ruminal ammonia-N concentration was higher for cows dosed with sucrose or lactose compared with those dosed with starch at 120 to 180 min after the dose (Figure 4).

\section{Plasma Metabolites}

Plasma insulin concentration was greater for sucrose compared with lactose and starch treatments since 30 min after the dose (Figure 5), and a transient difference was observed between lactose and starch treatments at 120 min after the dose. However, plasma concentrations of glucose, NEFA, and BHBA were not different among treatments (data are not shown) at any time points up to $180 \mathrm{~min}$ after the dose.

\section{Gene Expression}

Sucrose and lactose treatments, compared with starch treatment, increased relative mRNA abundance of NHE1 (0.91 and 0.97 vs. 0.70, respectively; Table 3), NHE2 (1.19 and 1.17 vs. 0.86, respectively), and ATP1 (1.16 and 1.17 vs. 0.75 , respectively). Sucrose treatment, compared with lactose and starch treatments, increased relative mRNA abundance of PAT1 (1.35 vs. 0.93 and 0.75 , respectively) and HMGCS1 (0.81 vs. 0.55 and 0.42 , respectively).

\section{DISCUSSION}

Ruminal doses of treatment carbohydrates did not decrease rumen $\mathrm{pH}$ as much as we had expected. We dosed $3.00 \mathrm{~kg}$ of sugars or $2.85 \mathrm{~kg}$ of starch along with $1.75 \mathrm{~kg}$ of alfalfa silage to temporarily challenge animals with excess fermentation, but rumen $\mathrm{pH}$ did not decrease drastically during a 180-min period immediately after the dose of treatment carbohydrates; all cows maintained rumen $\mathrm{pH}$ above 6.00 . This might be due to the strong buffering capacity of rumen digesta. 
Table 2. Primer and probe sequences and National Center for Biotechnology (NCBI) accession numbers for quantitative real-time PCR analysis

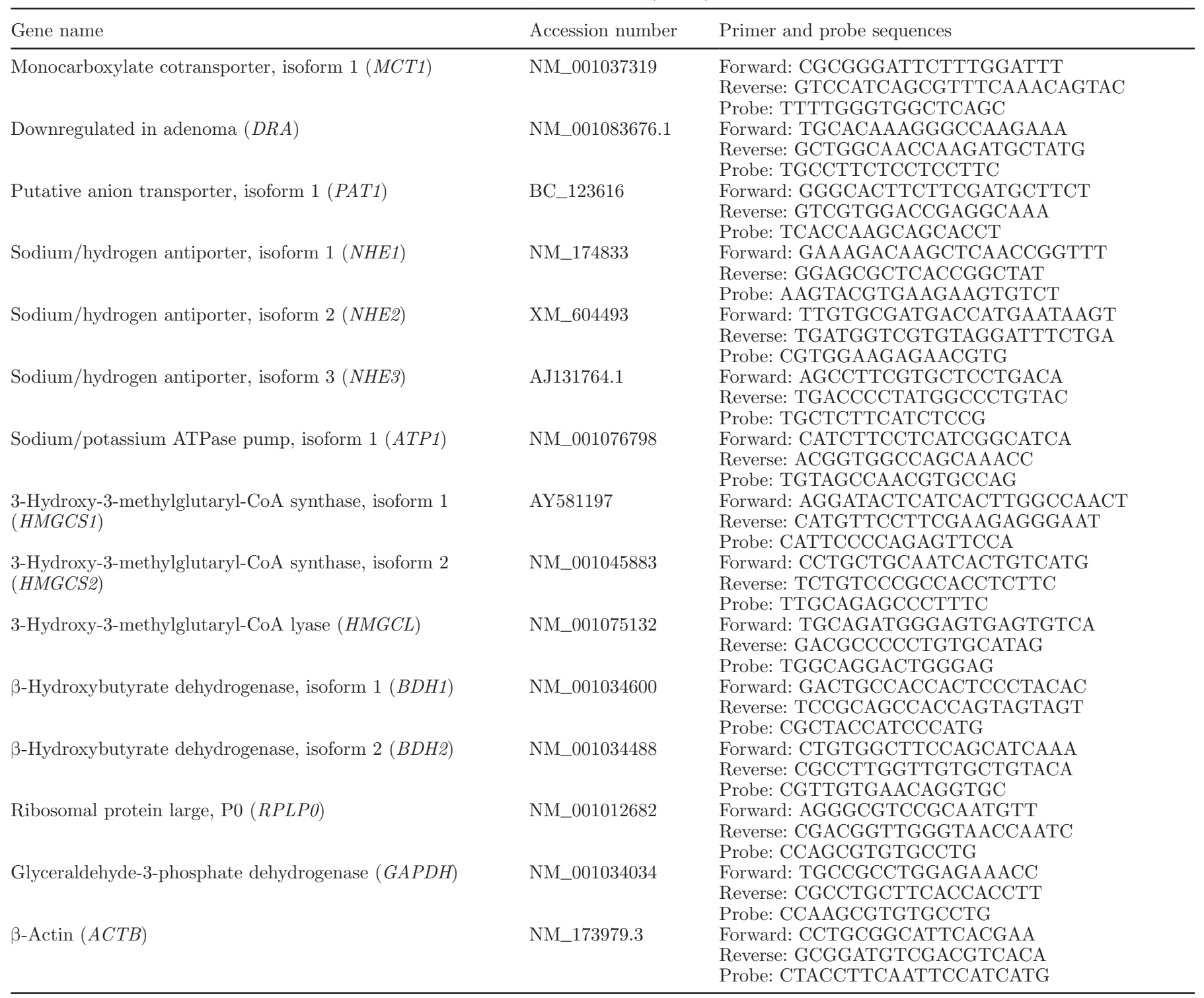

Animals were fed a high-forage basal diet, and because of the low energy requirement of animals (nonlactating, nonpregnant, mature cows), their DMI averaged 12.2 $\mathrm{kg}$ during the study, which is approximately $1.7 \%$ of their BW. Rumen $\mathrm{pH}$ averaged at 6.6 and total VFA concentration was less than $40 \mathrm{~m} M$ immediately before the dose of treatment carbohydrates. Although ruminal doses of sugars or starch increased total VFA concentration, the extent of increase is far lower than that typically observed for lactating dairy cows. We had been afraid that ruminal doses of highly fermentable carbohydrates would cause acute rumen acidosis, but our protocol might not be strong enough to challenge animals with excess fermentation, particularly for the starch treatment. The expected fermentation rate is slower for starch compared with sucrose or lactose, and the ruminal dose of starch might not have caused sufficient fermentation to alter rumen pH, total VFA concentration, and other response variables over the 180-min period. In addition, ruminal cannulas were opened every 30 min for rumen digesta sampling, which might have negatively affected activity of anaerobic microbial organisms in the rumen and reduced the extent of ruminal fermentation regardless of treatment. However, we detected significant treatments effects on many response variables, indicating that the experiment protocol was adequate to accomplish objectives of the current study. 




Figure 1. Ruminal $\mathrm{pH}$ for cows dosed with starch, lactose, or sucrose. Means \pm SEM with different letters differ $(P<0.05)$.

\section{Sucrose or Lactose vs. Starch}

Ruminal doses of sucrose or lactose increased total VFA concentration compared with that of starch, which can be attributed to rapid fermentation of sugars (Weisbjerg et al., 1998). Similarly, molar proportion of butyrate in ruminal fluid was greater for sucrose and lactose treatments compared with starch treatment. Although many in vitro studies demonstrated that sugar fermentation increases production of VFA, particularly butyrate, it is not consistently confirmed under in vivo conditions (Oba, 2011). Ruminal concentration of VFA is determined by the balance between its production

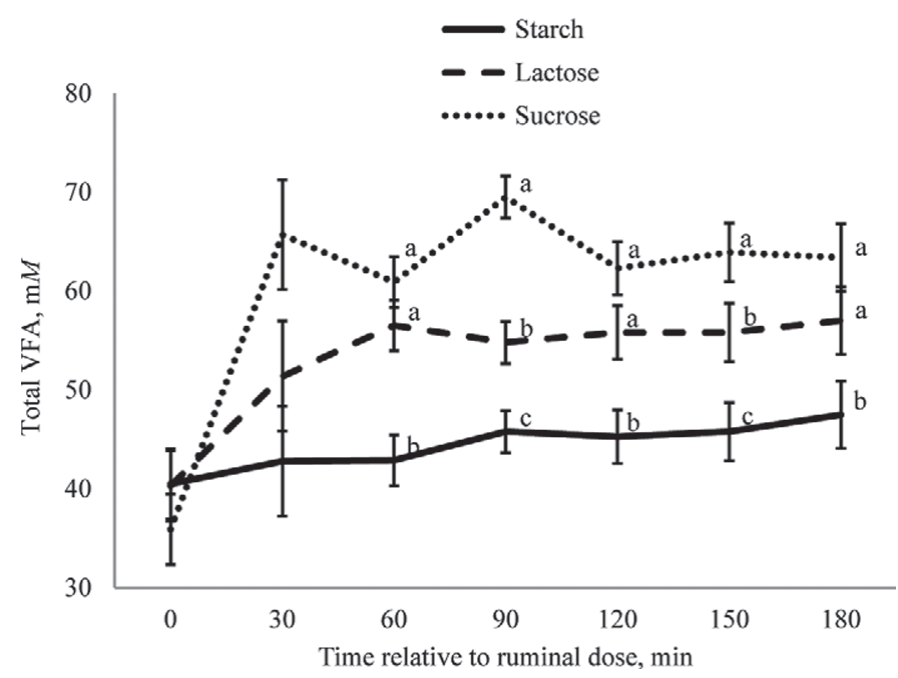

Figure 2. Ruminal concentration of total VFA for cows dosed with starch, lactose, or sucrose $(\mathrm{m} M)$. Means \pm SEM with different letters differ $(P<0.05)$.



Figure 3. Ruminal molar proportion of acetate (A), propionate (B), and butyrate (C) for cows dosed with starch, lactose, or sucrose (\%). Means \pm SEM with different letters differ $(P<0.05)$.

and removal, and VFA that are rapidly produced are also removed from the rumen rapidly by absorption or passage to the lower GI tract. In the current study, rumen fluid was sampled only for a 180-min period immediately after the dose of treatment carbohydrates, which allowed us to capture the time period that sugar fermentation affects the ruminal VFA profile to the greatest extent. Although collection of multiple rumen fluid samples accounting for diurnal variation is necessary to assess effects of rumen fermentation on overall animal performance, composited samples may fail to 


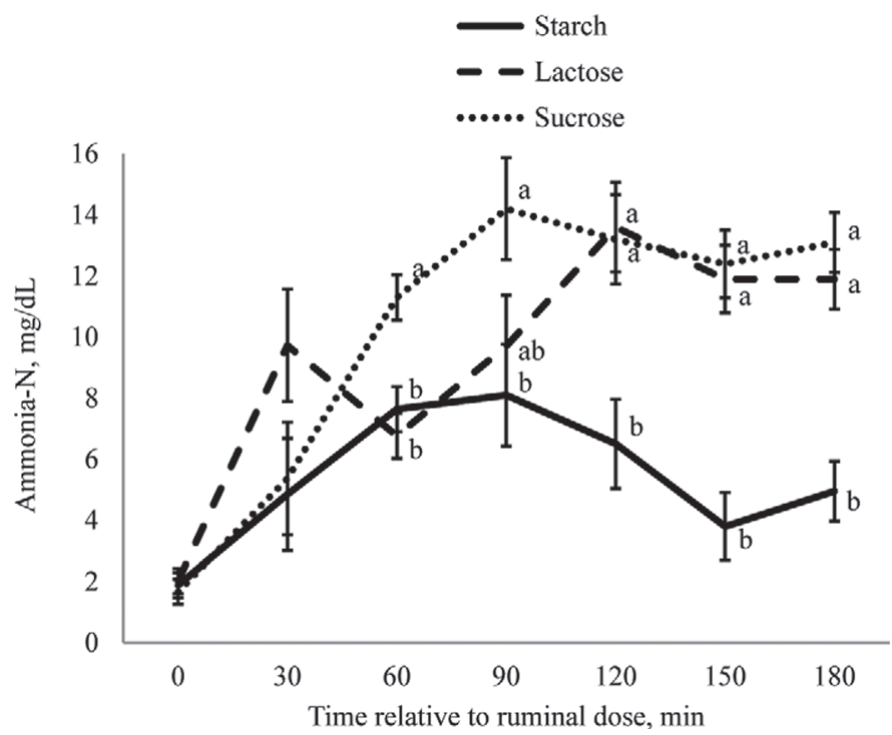

Figure 4. Ruminal concentration of ammonia- $\mathrm{N}$ for cows dosed with starch, lactose, or sucrose $(\mathrm{mg} / \mathrm{dL})$. Means \pm SEM with different letters differ $(P<0.05)$.

detect specific short-term effects of sugar fermentation on rumen fermentation. The current study suggests that feeding sugars can increase production of VFA, particularly butyric acid.

We had expected that rumen $\mathrm{pH}$ would be higher for sugar treatments because fermentation of sugars often increases butyrate production in the rumen (Oba, 2011). However, we observed lower rumen $\mathrm{pH}$ for the sucrose treatment in which butyrate concentration is highest. This might be attributed to the unique experimental settings for the current study (e.g., pulse dose of treatment carbohydrates and short-term observation

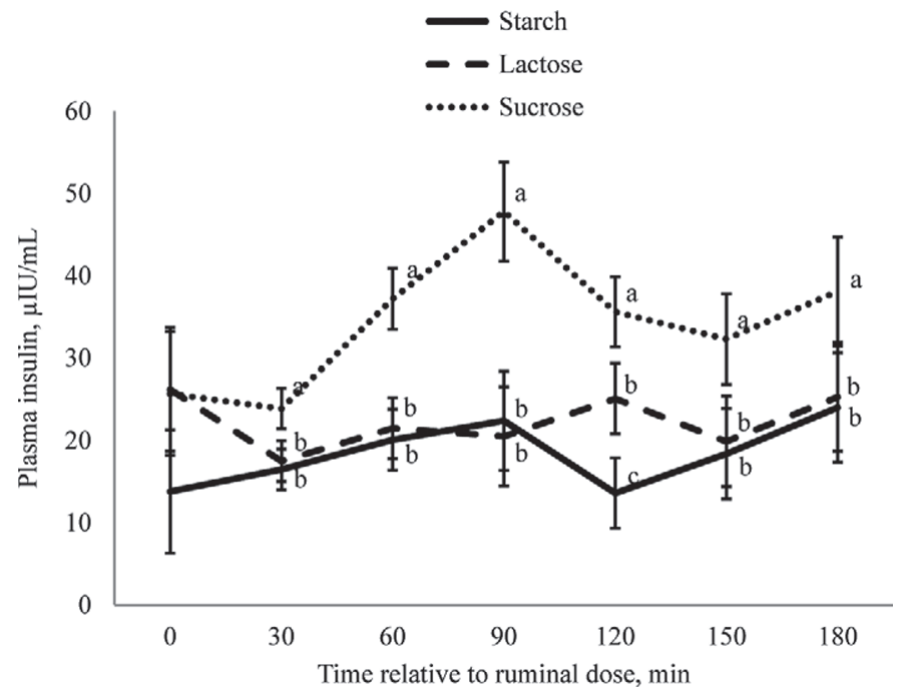

Figure 5. Plasma insulin concentration for cows dosed with starch, lactose, or sucrose $(\mu \mathrm{IU} / \mathrm{mL})$. Means \pm SEM with different letters differ $(P<0.05)$.

of rumen fermentation). Rumen $\mathrm{pH}$ is determined by the balance of acid production and acid removal via neutralization, absorption, and passage (Allen, 1997), and extensive fermentation of sucrose might have been the most dominant factor determining the short-term acid balance in the rumen regardless of differences in the VFA profile.

Relative mRNA abundance of NHE1 and NHE2 in ruminal papillae was greater for sucrose and lactose treatments compared with starch treatment. The NHE are transporters releasing $\mathrm{H}^{+}$to the lumen or extracellular space, and taking up $\mathrm{Na}^{+}$into epithelial cells;

Table 3. Relative mRNA abundance of genes involved in intracellular $\mathrm{pH}$ regulation and VFA metabolism for cows that were ruminally dosed with starch, lactose, or sucrose

\begin{tabular}{lccccr}
\hline Gene $^{1}$ & Starch & Lactose & Sucrose & SE & $P$-value \\
\hline NHE1 & $0.70^{\mathrm{b}}$ & $0.97^{\mathrm{a}}$ & $0.91^{\mathrm{a}}$ & 0.103 & 0.01 \\
NHE2 & $0.86^{\mathrm{b}}$ & $1.17^{\mathrm{a}}$ & $1.19^{\mathrm{a}}$ & 0.127 & 0.02 \\
NHE3 & 0.79 & 0.86 & 0.71 & 0.157 & 0.63 \\
ATP1 & $0.75^{\mathrm{b}}$ & $1.17^{\mathrm{a}}$ & $1.16^{\mathrm{a}}$ & 0.092 & $<0.01$ \\
PAT1 & $0.75^{\mathrm{b}}$ & $0.93^{\mathrm{b}}$ & $1.35^{\mathrm{a}}$ & 0.137 & 0.01 \\
DRA & 0.86 & 0.98 & 0.86 & 0.124 & 0.72 \\
MCT1 & 0.83 & 1.09 & 1.12 & 0.113 & 0.17 \\
HMGCS1 & $0.42^{\mathrm{b}}$ & $0.55^{\mathrm{b}}$ & $0.81^{\mathrm{a}}$ & 0.104 & 0.02 \\
HMGCS2 & 1.24 & 1.19 & 1.30 & 0.111 & 0.77 \\
HMGL & 1.04 & 0.94 & 0.97 & 0.068 & 0.59 \\
BDH1 & 1.01 & 1.07 & 1.00 & 0.077 & 0.80 \\
BDH2 & 1.04 & 1.21 & 1.19 & 0.122 & 0.47 \\
\hline
\end{tabular}

${ }^{\mathrm{a}, \mathrm{b}}$ Means within a row followed by different superscripts differ $(P<0.05)$.

${ }^{1}$ NHE1, NHE2, NHE3 $=$ sodium hydrogen exchanger isoforms 1,2 , and $3 ; A T P 1=\mathrm{Na}^{+} / \mathrm{K}^{+}$ATPase pump isoform 1; PAT1 = putative anion transporter isoform 1; DRA = downregulated in adenoma; $M C T 1=$ monocarboxylate cotransporter, isoform 1; HMGCS1, HMGCS2 = 3-hydroxy 3-methylglutaryl coenzyme A synthase isoforms 1 and 2; HMGL = 3-hydroxy-3-methylglutaryl-CoA lyase; BDH1, BDH2 = $\beta$-hydroxybutyrate dehydrogenase isoforms 1 and 2 . 
NHE1 is primarily found in the stratum granulosum, whereas NHE2 is mainly located on in the stratum basale, stratum spinosum, and stratum granulosum (Graham et al., 2007). Mooney (2006) showed that postprandial change in $\mathrm{Na}^{+}$concentration in ruminal fluid was negatively related to meal size, indicating that $\mathrm{Na}^{+}$absorption increases with greater fermentation in the rumen. In addition, $\mathrm{Na}^{+}$absorption by ruminal epithelial cells increases during the time course of their adaptation to a highly fermentable diet (Etschmann et al., 2009), which suggests that greater NHE activity is considered an adaptation to enhanced fermentation in the rumen. Butyrate promotes upregulation of NHE (Kiela et al., 2001; Subramanya et al., 2007), and this is consistent with our findings; ruminal doses of sucrose or lactose, which had higher molar proportions of butyrate concentration in ruminal fluid, had greater mRNA abundance of NHE.

Greater NHE activities are expected to increase proton release back to the rumen, which decreases local $\mathrm{pH}$ near the stratum granulosum and increases undissociated form of VFA there, and these effects may increase absorption of VFA by simple diffusion (Graham et al., 2007; Connor et al., 2010). Many in vivo studies reported that feeding sugars does not decrease overall daily rumen $\mathrm{pH}$ despite rapid fermentation and potential short-term reductions in rumen $\mathrm{pH}$ (Oba, 2011). This may be attributed to possible NHE activities that promote rapid VFA absorption by simple diffusion. Schlau et al. (2012) showed that significant variation existed in rumen $\mathrm{pH}$ and VFA profile among steers force-fed a high grain diet, and that mRNA abundance of NHE in ruminal epithelial cells was greater for steers that had higher rumen $\mathrm{pH}$, lower ruminal VFA concentration, and higher butyrate concentration. Storm et al. (2011) reported that ruminal infusion of butyrate increases net portal flux of propionate, which indicates rapid VFA absorption.

Relative mRNA abundance of ATP1 was also greater for sucrose and lactose treatments compared with starch treatment, which is consistent with expected greater NHE activities. Greater NHE activities increase $\mathrm{Na}^{+}$concentration in the cell, and ATP1 needs to pump out $\mathrm{Na}^{+}$against the concentration gradient to maintain low intracellular $\mathrm{Na}^{+}$concentration. Storm et al. (2011) reported that ruminal infusion of butyrate increased local blood flow to ruminal epithelia, and their observations may be explained by expected ATP1 activity. As the action of ATP1 requires energy, the oxidative metabolism that generates $\mathrm{CO}_{2}$ is expected to increase with greater ATP1 activities, and $\mathrm{CO}_{2}$ as a vasodilator is expected to increase local blood flow to ruminal epithelia.
Although the activity of NHE1, NHE2, and ATP1 was not directly measured in the current study, possible physiological implications of upregulation of those genes were consistent with other studies (Storm et al., 2011; Schlau et al., 2012). However, Aschenbach et al. (2011) suggested that action of apical NHE may contribute to subacute ruminal acidosis by increasing the ruminal proton load. The effects of NHE on rumen $\mathrm{pH}$ warrant further investigation.

Ammonia-N concentration in the rumen was greater for sucrose and lactose treatments compared with starch treatment, which is contrary to previous reports. Broderick et al. (2008) and DeFrain et al. (2006) reported that increasing dietary sucrose or lactose content decreased ammonia- $\mathrm{N}$ concentration in the rumen, respectively. Feeding high-sugar diets may decrease ruminal ammonia- $\mathrm{N}$ concentration if readily fermentable OM limits microbial protein production (Oba, 2011). Therefore, greater ammonia- $\mathrm{N}$ concentration for the sugar treatments indicates that microbial protein production might not have been limited by availability of fermentable carbohydrates under the current experimental settings. Alternatively, greater VFA concentration for the sugar treatments might have stimulated urea recycling to the rumen (Abdoun et al., 2010), temporarily increasing ammonia-N concentration in the rumen.

\section{Sucrose vs. Lactose}

The current study showed that rumen $\mathrm{pH}$ was affected only by the sucrose treatment during the third hour after the dose, but not by the lactose treatment, suggesting that sucrose ferments faster than lactose. This observation is consistent with Weisbjerg et al. (1998) who reported faster hydrolysis rate of sucrose compared with lactose, and Sutton (1968) who showed that glucose and fructose ferment faster than galactose. In addition, molar proportion of acetate was lower and that of propionate was higher for sucrose treatment compared with lactose treatment. In literature, some studies reported that partially replacing dietary starch sources with lactose decreased propionate concentration in rumen fluid (Schingoethe et al., 1980; DeFrain et al. 2004) while feeding fructose, a component of sucrose, increased the molar proportion of propionate in rumen fluid (Chamberlain et al., 1993). Plasma insulin concentration during a 3 -h period after the ruminal dose of treatment was higher for sucrose compared with starch and lactose, and this is consistent with greater propionate concentration in rumen fluid for sucrose treatment as propionate can stimulate insulin release (Sano et al., 1995). Both sucrose and lactose are often collectively 
considered as sugar, but the current study as well as previous studies in literature indicates that fermentation rates are different depending on the type of sugar, and their effects on rumen $\mathrm{pH}$ and VFA profile are also variable.

Expression of PAT1 was increased only by sucrose compared with starch. The PAT1 is a transport protein located in apical cell membrane, and facilitates transport of dissociated form of VFA into epithelial cells in exchange of bicarbonate ion back to the rumen (Connor et al., 2010). It is not clear whether mRNA abundance of PAT1 is related to its activities, but if so, greater PAT1 activity is expected to increase VFA absorption and rumen $\mathrm{pH}$ by facilitating acid neutralization. However, rumen $\mathrm{pH}$ was lower for sucrose treatment, which is not consistent with expected greater activity of PAT1.

The enzyme HMGCS1 catalyzes butyrate metabolism in the cytosol for cholesterol synthesis, whereas HMGCS2 is an enzyme in the mitochondria for BHBA synthesis. Lane et al. (2002) reported that abundance of mRNA of HMGCS (isoform type was not specified) increased with the age of lamb, indicating its positive relationship with BHBA production (Lane et al., 2000). In the current study, sucrose treatment increased mRNA abundance of $H M G C S 1$, but not that of HMGCS2. Although sucrose treatment increased butyrate concentration in rumen fluid, it did not affect plasma BHBA concentration. This may be attributed to the lack of treatment effect on HMGCS2. The current study showed that sucrose treatment, which decreased rumen $\mathrm{pH}$, upregulated HMGCS1. However, previous research reported that increasing diet fermentability downregulated HMGCS1 in ruminal epithelial cells of mature cows (Steele et al., 2011) or weaned calves (Laarman et al., 2012). The effects of rumen fermentation on butyrate metabolism in ruminal epithelial cells are not consistent in the literature, and warrant further investigation.

Although it is possible that type of sugar affects the metabolism of ruminal epithelial cells, gene expression data from the current study need to be interpreted with caution. Animals were fed a high-forage diet containing barley silage at $83 \%$ of dietary DM during the study. Although the diet contains sucrose and lactose $(2.1 \%$ each on a DM basis), microbial adaptation may not be sufficient and ruminal dose of sucrose or lactose may not reflect actual metabolism in ruminal epithelial cells where sucrose or lactose is included in diets at a high concentration. Nonetheless, it is noteworthy that several key genes involved in butyrate metabolism and intracellular $\mathrm{pH}$ regulation are affected, and further research is warranted to confirm findings from the current study.

\section{CONCLUSIONS}

Ruminal doses of sucrose or lactose increased total VFA concentration, molar proportion of butyrate in ruminal fluid, and relative mRNA abundance of genes that facilitate absorption of fermentation acids compared with ruminal doses of starch. However, treatment effects on rumen $\mathrm{pH}$, molar proportion of acetate and propionate in ruminal fluid, plasma insulin concentration, and expression of some genes in ruminal epithelial cells were different between sucrose and lactose. Although sucrose and lactose are often considered collectively as sugar, effects of feeding sugars on ruminal fermentation and subsequent metabolism in ruminal epithelial cells may vary depending on the type of sugar.

\section{ACKNOWLEDGMENTS}

This study is supported by Alberta Milk (Edmonton, $\mathrm{AB}$, Canada) and Natural Sciences and Engineering Research Council of Canada (Ottawa, ON, Canada). The authors thank Y. Sun, J. Haisan, X. Gao, and A. Ruiz-Sanchez (University of Alberta, Edmonton, AB, Canada) for their assistance with collection and analysis of samples.

\section{REFERENCES}

Abdoun, K., F. Stumpff, I. Rabbani, and H. Martens. 2010. Modulation of urea transport across sheep rumen epithelium in vitro by SCFA and $\mathrm{CO}_{2}$. Am. J. Physiol. Gastrointest. Liver Physiol. 298:G190-G202.

Allen, M. S. 1997. Relationship between fermentation acid production in the rumen and the requirement for physically effective fiber. J. Dairy Sci. 80:1447-1462.

Aschenbach, J. R., G. B. Penner, F. Stumpff, and G. Gabel. 2011. Ruminant Nutrition Symposium: Role of fermentation acid absorption in the regulation of ruminal pH. J. Anim. Sci. 89:1092-1107.

Broderick, G. A., N. D. Luchini, S. M. Reynal, G. A. Varga, and V. A. Ishler. 2008. Effect on production of replacing dietary starch with sucrose in lactating dairy cows. J. Dairy Sci. 91:4801-4810.

Chamberlain, D. G., S. Robertson, and J. J. Choung. 1993. Sugars versus starch as supplements to grass silage: Effects on ruminal fermentation and the supply of microbial protein to the small intestine, estimated from the urinary excretion of purine derivatives, in sheep. J. Sci. Food Agric. 63:189-194.

Chomczynski, P., and N. Sacchi. 1987. Single-step method of RNA isolation by acid guanidinium thiocyanate phenol chloroform extraction. Anal. Biochem. 162:156-159.

Connor, E. E., R. W. Li, R. L. Baldwin VI, and C. Li. 2010. Gene expression in the digestive tissues of ruminants and their relationships with feeding and digestive processes. Animal 4:993-1007.

DeFrain, J. M., A. R. Hippen, K. F. Kalscheur, and D. J. Schingoethe. 2004. Feeding lactose increases ruminal butyrate and plasma $\beta$-hydroxybutyrate in lactating dairy cows. J. Dairy Sci. 87:2486-2494.

DeFrain, J. M., A. R. Hippen, K. F. Kalscheur, and D. J. Schingoethe. 2006. Feeding lactose to increase ruminal butyrate and the metabolic status of transition dairy cows. J. Dairy Sci. 89:267-276.

Etschmann, B., A. Suplie, and H. Martens. 2009. Change of ruminal sodium transport in sheep during dietary adaptation. Arch. Anim. Nutr. 63:26-38.

Graham, C., I. Gatherar, I. Haslam, M. Glanville, and N. L. Simmons. 2007. Expression and localization of monocarboxylate transporters 
and sodium/proton exchangers in bovine rumen epithelium. Am. J. Physiol. 292:R977-R1007.

Heldt, J. S., R. C. Cochran, G. K. Stokka, C. G. Farmer, C. P. Mathis, E. C. Tigemeyer, and T. G. Nagaraja. 1999. Effects of different supplemental sugars and starch fed in combination with degradable intake protein on low-quality forage use by beef steers. J. Anim. Sci. 77:2793-2802.

Khorasani, G. R., E. K. Okine, and J. J. Kennelly. 1996. Forage source alters nutrient supply to the intestine without influencing milk yield. J. Dairy Sci. 79:862-872.

Kiela, P. R., E. R. Hines, J. F. Collins, and F. K. Ghishan. 2001. Regulation of the rat NHE3 gene promoter by sodium butyrate. Am. J. Physiol. 281:G947-G956.

Laarman, A. H., A. L. Ruiz-Sanchez, T. Sugino, L. L. Guan, and M. Oba. 2012. Effects of feeding a calf starter on molecular adaptations in the ruminal epithelium and liver of Holstein dairy calves during the weaning transition. J. Dairy Sci. 95:2585-2594.

Lane, M. A., R. L. Baldwin VI, and B. W. Jesse. 2000. Sheep rumen metabolic development in response to different dietary treatments. J. Anim. Sci. 78:1990-1996.

Lane, M. A., R. L. Baldwin VI, and B. W. Jesse. 2002. Developmental changes in ketogenic enzyme gene expression during sheep rumen development. J. Anim. Sci. 80:1538-1544.

Leek, B. F. 1993. Digestion in the ruminant stomach. Pages 387-416 in Dukes' Physiology of Domestic Animals. 11th ed. M. J. Swenson and W. O. Reece, ed. Cornell University Press, Ithaca, NY.

Mooney, C. S. 2006. Regulation of the ruminal environment by lactating dairy cows. PhD Diss. Michigan State Univ., East Lansing.

Oba, M. 2011. Effects of feeding sugars on productivity of lactating dairy cows. Can. J. Anim. Sci. 91:37-46.

Penner, G. B., K. A. Beauchemin, and T. Mutsvangwa. 2006. An evaluation of the accuracy and precision of a stand-alone submersible continuous ruminal pH measurement system. J. Dairy Sci. $89: 2132-2140$

Penner, G. B., L. L. Guan, and M. Oba. 2009. Effect of feeding Fermenten on ruminal fermentation in lactating Holstein cows fed two dietary sugar concentrations. J. Dairy Sci. 92:1725-1733.

Penner, G. B., and M. Oba. 2009. Increasing dietary sugar concentration may improve dry matter intake, ruminal fermentation, and productivity of dairy cows in the postpartum phase of the transition period. J. Dairy Sci. 92:3341-3353.

Ribeiro, C. V. D. M., S. K. R. Karnati, and M. L. Eastridge. 2005 Biohydrogenation of fatty acids and digestibility of fresh alfalfa or alfalfa hay plus sucrose in continuous culture. J. Dairy Sci. 88:4007-4017.

Sano, H., S. Hayakawa, H. Takahashi, and Y. Terashima. 1995. Plasma insulin and glucagon responses to propionate infusion into femoral and mesenteric veins in sheep. J. Anim. Sci. 73:191-197.
Schingoethe, D. J., E. W. Skyberg, and R. W. Bailey. 1980. Digestibility, mineral balance, and rumen fermentation by steers of rations containing large amounts of lactose or dried whey. J. Dairy Sci. 63:762-774.

Schlau, N., L. L. Guan, and M. Oba. 2012. The relationship between rumen acidosis resistance and expression of genes involved in regulation of intracellular $\mathrm{pH}$ and butyrate metabolism of ruminal epithelial cells in steers. J. Dairy Sci. 95:5866-5875.

Sniffen, C. J., J. D. O'Connor, P. J. Van Soest, D. G. Fox, and J. B. Russell. 1992. A net carbohydrate and protein system for evaluating cattle diets: II. Carbohydrate and protein availability. J. Anim. Sci. 70:3562-3577.

Steele, M. A.. G. Vandervoort, O. AlZahal, S. E. Hook, J. C. Matthews, and B. W. McBride. 2011. Rumen epithelial adaptation to high-grain diets involves the coordinated regulation of genes involved in cholesterol homeostasis. Physiol. Genomics 43:308-316.

Storm, A. C., M. D. Hanigan, and N. B. Kristensen. 2011. Effects of ruminal ammonia and butyrate concentrations on reticuloruminal epithelial blood flow and VFA absorption kinetics under washed reticulorumen conditions in lactating dairy cows. J. Dairy Sci. 94:3980-3994.

Subramanya, S. B., V. M. Rajendran, P. Srinivasan, N. S. Nanda Kumar, B. S. Ramakrishna, and H. J. Binder. 2007. Differential regulation of cholera toxin-inhibited $\mathrm{Na}-\mathrm{H}$ exchange isoforms by butyrate in rat ileum. Am. J. Physiol. Gastrointest. Liver Physiol. 293:G857-G863.

Sun, Y., and M. Oba. 2014. Effects of feeding a high-fiber byproduct feedstuff as a substitute for barley grain on rumen fermentation and productivity of dairy cows in early lactation. J. Dairy Sci 97:1594-1602.

Sutton, J. D. 1968. The fermentation of soluble carbohydrates in rumen contents of cows fed diets containing a large proportion of hay. Br. J. Nutr. 22:689-712

Vallimont, J. E., F. Bargo, T. W. Cassidy, N. D. Luchini, G. A. Broderick, and G. A. Varga. 2004. Effects of replacing dietary starch with sucrose on ruminal fermentation and nitrogen metabolism in continuous culture. J. Dairy Sci. 87:4221-4229.

Vandesompele, J., K. De Preter, F. Pattyn, B. Poppe, N. Van Roy, A. De Paepe, and F. Speleman. 2002. Accurate normalization of real-time quantitative RT-PCR data by geometric averaging of multiple internal control genes. Genome Biol. 3:0034.1-0034.11.

Weisbjerg, M. R., T. Hvelplund, and B. M. Bibby. 1998. Hydrolysis and fermentation rate of glucose, sucrose and lactose in the rumen. Acta Agric. Scand. A Anim. Sci. 48:12-18. 